
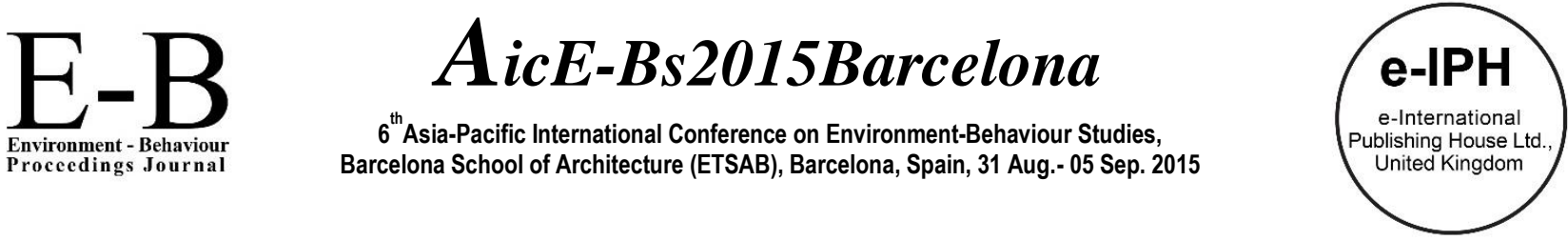

\title{
Defining Place Attachment in Asian Urban Places through Opportunities for Social Interactions
}

\author{
Norsidah Ujang * \\ Department of Landscape Architecture, Faculty of Design and Architecture, Universiti Putra Malaysia, Serdang 43400, Selangor, Malaysia
}

\begin{abstract}
Despite the high intensity of urban dwellers and the growing needs for socialization outdoor, the opportunity for interaction is limited due to the lack of public open spaces. This paper discusses the use of public open spaces in a city of Kuala Lumpur and how it shapes users' attachment. Field observations and face to face interviews were conducted to examine the opportunities for social activities and pattern of users' engagement. The findings indicate the incapability of the places to provide multifunctional spaces for diverse interactions while the social attachment to the places is strongly defined by interaction with familiar people in place.

(C) 2016. The Authors. Published for AMER ABRA by e-International Publishing House, Ltd., UK. Peer-review under responsibility of AMER (Association of Malaysian Environment-Behaviour Researchers), ABRA (Association of Behavioural Researchers on Asians) and cE-Bs (Centre for Environment-Behaviour Studies, Faculty of Architecture, Planning \& Surveying, Universiti Teknologi MARA, Malaysia.
\end{abstract}

Keywords: Place attachment; public places; social needs; social interaction

\section{Introduction}

Between 1990 and 2010, the number of Asian urban inhabitants reaches 754 million, which constitute more than the total population of the United States, and Western Europe combined (UN-HABITAT, 2011). The social needs increases and so as the awareness about the protection and improvement of the public realm for a better social life. Social sustainability defines people's quality of life and describes the extent to which a neighborhood supports individual and collective well-being. The need is to provide public infrastructure to support a social and cultural life, opportunities for people to get involved, and functions for the place and the community to evolve. The human interaction with urban places denotes the importance of the place as a social space. Urban sociologist Oldenburg (1999) defined a third place as a place of refuge other than the home or workplace where people can regularly visit and commune with friends, neighbors, coworkers, and even strangers. A third place is visited by regulars, to meet old friends and make new ones (Mehta, 2013). Through time, the places create personal or social meanings that reflect the cultural identity of a society. As a result, place attachment developed which positively benefit both personal and social life (Ujang \& Zakariya, 2015). The objective of this paper is to examine the opportunities for social activities and

\footnotetext{
* Corresponding author. Tel.: +6-03-89464071; fax: +6-03-89480017

E-mail address: norsidah@upm.edu.my
}

(C) 2016. The Authors. Published for AMER ABRA by e-International Publishing House, Ltd., UK. Peer-review under responsibility of AMER (Association of Malaysian Environment-Behaviour Researchers), ABRA (Association of Behavioural Researchers on Asians) and cE-Bs (Centre for EnvironmentBehaviour Studies, Faculty of Architecture, Planning \& Surveying, Universiti Teknologi MARA, Malaysia.

DOl: http://dx.doi.org/10.21834/e-bpj.v1i1.191 
Ujang, N., / $6^{\text {th }}$ AicE-Bs2015Barcelona, Spain, 30 Aug.- 04 Sep. 2015 / E-BPJ, Maiden Issue, 1(1) June 2016 (pp.28-35)

engagement pattern of the urban users. The aim is to understand the way people relate to public spaces as social spaces and their roles in supporting place attachment.

\section{Literature Review}

\subsection{Social sustainability and the quality of public spaces}

Social sustainability of a city refers to the development and growth that are suitable to the harmonious evolution of civil society. It fosters a helpful environment for more cohabitation of culturally and socially diverse groups (Polése and Stren, 2000). The aim is to encourage social integration, which promote a better quality of life for all segments of the population. Issues on social sustainability highlight the importance of the public spaces as social spaces. It promotes the development of the feeling of affiliation and belonging to a place and promotes strong social cohesion could be developed (Francis et al., 2012).

Social environments refer to the immediate physical surroundings, social relationship, and culture within defined groups of people to function and interact (Barnett \& Casper, 2001). Human-place interaction influences the perception of the physical attributes and activities that form place identity (Ujang \& Samsuddin, 2008). The experiences of people derived from their interactions with the associated place attribute (Marans, 2012). A good place reflects a positive sense of attachment, dependence and identity that people established about the place they live (Dempsey et al., 2011) that facilitates social integration. Therefore, the quality of the public spaces influences resident's outdoor activities (Adams and Tiesdell, 2008).

Safety, pleasurable, sociability, comfort, meaningful activities, connectivity, and inclusiveness are indicators for a socially responsive pedestrian environment (Mehta, 2014). Mehta's study on the quality of main streets as 'third place' indicated that the users who regularly used the streets valued the outdoor sitting space provided by businesses for relaxation and people watching. The combination of food and social activity supported by outdoor seating made people stay longer on the street (Mehta, 2010).

These attributes provided physical comfort with ample amenities, pedestrian facilities and shaded space and shelter that suitable for the tropical environment. The edges of streets relate to social activity, and it should be accessible and permeable (Thwaites et al., 2009). In a closer examination of attachment to place, social interaction has a major contribution to place attachment to the traditional street in Kuala Lumpur (Ujang, 2014) compared to the physical elements. This paper further dwells into how these activities could support social interactions and the form of attachment to the places.

\subsection{Human needs for interaction and place attachment}

Public open spaces are designed to intercept human needs (Al-Bishawi \& Ghadban, 2011), and social interaction is one of the most important one (Cacioppo and Patrick, 2008). There is also a need to participate in meaningful activities that give identity to individuals and groups. Also include the need to move from one place to another with ease and comfort and the need to feel attached to certain people and places. Those include opportunities to walk, to sit outdoors, to stand, to stay, to talk and listen and to play and exercise. (Gehl, 2009).

The inhabitant should have equal opportunities to participate in the city activities. Inclusiveness also enhances community feelings, and the sense of ownership towards the city, and the sense of belonging to a place. Place attachment is evident in the functional bonding between people and places described as place dependence (Stokol and Shumaker, 1981). The emotional and the social attachment also developed due to frequency and length of engagement (Ujang and Zakariya, 2015). However, in the case of multi-cultural context of Asian cities, the role of public spaces in developing social attachment through a continuous sense of interaction between people and places is difficult to define. The Asian spaces and urbanism is multi-layered and complex. The situation requires an understanding of the particularities of the spaces and character grounded in the experience and the dynamic activities of the people in place (Pirera and Tang, 2013). What attributes of the places support social attachment and the sense of belonging to the communities, in particular, Asian context? The Malaysian streetscape can be understood as a contact and interface space between different racial groups (Utaka and Fawzi, 2010). How do the people express their attachment through social interaction? Could the spaces support the social contacts within the diversity of activities?

The place attachment concept is placed within the psychological (emotion and feeling) as well as a functional (dependence) domain of environmental experience. Place perception and attachment determine the social and cultural value of a place particularly to its inhabitants (Ujang, 2010). In the context of this paper, place dependence (engagement) will be examined to understand the interaction between people and places that could be a vital factor in sustaining continuous activities. 


\section{Methods}

The study adopted qualitative inquiry in examining the way people use spaces, the interaction and its influence on place attachment. Field observations were conducted to understand the use of spaces including streets, parks, and small urban spaces. Assessment of the place as social spaces was done together with descriptions of the users' activities in the area. 15 respondents were randomly selected using a semi-structured format based on convenience and willingness to share views and experience of the places. The respondents include shopowners, workers/shopkeepers, shoppers, personnel/ authority workers, local visitors and students who identified as the main user groups in the Kuala Lumpur city center. The study areas are Jalan Masjid India, Dataran Merdeka, Medan Pasar, and Central Market. These areas are historical places that receive the highest concentration of visitors and tourists as pedestrians. Gender, age and length of engagement with the city and their roles in the area, were also recorded. Due to the limitation of time, the size of the samples and study areas was relatively small. Therefore, the findings will only apply to urban places with similar characteristics in other cities. The cross-analysis of the qualitative data allows the researcher to identify the functions of social spaces and attachment expressed as a result of the people's interaction and engagement with the places through meaningful activities.

\section{Results and Discussion}

\subsection{Place attachment was influenced by the length of engagement and opportunity to use spaces and places for activities}

The importance of the spaces relates to the types of users' engagement to the places. Those who depend on the places for economic sustenance (e.g. as painter or vendors) found the public spaces very important to their life and spend more than eight hours in the area on the daily basis. They expressed that the vitality of the places as shopping as well as tourism attraction provided the opportunities for different types of people to interact. With the long-term engagement, many refused to be relocated to other places also due to the availability of public and transport facilities. Despite frequent mentioning on the good accessibility of the public spaces via rail transport. They found the place was unwelcoming due to the lack of disabled facilities and public facilities such as public toilets. There is also a need to improve praying spaces ('surau') in the area since the majority of the users are Malays as Muslims. One of the respondents mentioned the need for disabled facilities:

"We need wider sidewalk and path for OKU. They also want to do leisure activity, I have a sister who is an OKU, I wish I could walk along with my sister. If the place has OKU facilities suitable parking dedicated for the OKU, I may consider going there." [R9] Female, aged 20 -student

"The praying space should be improved. Even though we have the mosque here, its too pack during peak hours. Also, the public toilets are limited. I am satisfied with the rest, the public transport is already in place, the commuter station is close by." [R8] Female, aged 24 -student

Streets, public parks, and plaza provide an opportunity for people to interact. In general, streets in the city center of Kuala Lumpur are used mainly for movement and linkages. Activities were concentrated on the threshold areas between streets and buildings that in some situations function as eating spaces extended from the shops. People mainly engaged in passive activities there while others will enter the shopping malls for shopping and recreation. Social interaction therefore very limited to the indoor activities. In the case of parks, the spaces are mainly active during the lunchtime and after working hours. Some of the spaces are underutilized because there is no shade to encourage longer stay.

"This square is one of the open spaces, like a green field in the city center. It's really good to sit here. There are too many shopping malls in KL, less outdoor area, however." [R15] Female, aged 22, Local Visitor

"I am happy shopping here. But I feel a bit uncomfortable because there are many people on weekends. Its crowded even to walk, limited space." [R1] Female, aged 26 Local Visitor 
Ujang, N., / $6^{\text {th }}$ AicE-Bs2015Barcelona, Spain, 30 Aug.- 04 Sep. 2015 / E-BPJ, Maiden Issue, 1(1) June 2016 (pp.28-35)

"I have seen more indoor spaces for activity, but you have to pay. It is better to create public events because they are free. People will come. If possible, we could create more public open spaces like a square in the city center." [R14] Male aged 21, Local Visitor

Social activities were categorized as necessary, optional and social (Gehl, 1971). The physical environment has an influence on the activities. The activities happened in the public spaces, in particular, streets that are mainly for pedestrians moving to a certain destination. The activities are mainly passive (seeing and hearing each other) rather than interactive (elaborate social contacts - greeting, conversation, discussion). In the case of small pocket spaces, it was observed that interactive activities increased. The highest level of social activities occurred in street vending areas where selling, buying and bargaining activities took place. The social and economic dependency on the place was evident in particular to the street vendors in Jalan Masjid India.

The diversity of activities attracts people to interact. However, due to very limited space, streets do not allow for active interaction. The public spaces that linked to the commercial activities received greater intensity and variety of users compared to isolated spaces that may be attractive to tourists but not the local people. As mentioned below:

"For me, this place is too crowded, with cars, tall buildings. We feel hot staying outdoor. The air is trapped, with no air. If there are open spaces, green space like this, I feel a bit calm. So, probably we can increase open spaces like Merdeka Square in the city center of Kuala Lumpur." [R6]Female, aged 19-student

The traditional streets reflect the dominance of particular ethnic groups while the most modern places have a mixture of users from all ethnic background and tourists. This condition may be due to the availability of the goods appropriate to the needs of the users. The commercial and social activities during weekly night market and festivals associated with the ethnic group of Malay, Indian, Indian Muslim and Chinese. The normal atmosphere will turn into a fiesta and events that heighten the level of interaction, from passive to more active, elaborate and mixed. The issue is the failure to accommodate the people to comfortably engage in the activities despite people attachment to the events.

"The best was when there was a festival; it was a huge event. Hari Raya, Deepavali and Chinese New Year open houses. There are eating feast, for example, recently there was Chinese New year celebration, there was a lion dance, they gave away oranges, 'ang pau'." [R7] Female, aged 19, Shopkeeper.

Based on the observation, the users' length of engagement varied according to the reasons why they were there. Those who worked and studied in the areas showed greater concern about the places. They were very familiar with the places and spent time meeting and gathering with friends and relatives there. They are those who are more critical towards events and activities and their impact on the social life of people in the areas. Some mentioned the very limited activities they could do and the coming of 'immigrants' that makes them avoid places that they once used to go to get together with friends.

\subsection{Lack of spaces for social activities and less interactive contacts}

How to make people stay longer in public spaces? The use of streets as social spaces is reduced due to the lack of stimulation and inadequacy of spaces for multi-activities. The pedestrianized streets allow for a greater number of activities to take place (e.g., Jalan Masjid India, Jalan Petaling). However, there is no integration of other public spaces to the street to increase the diversity of interactions in the area. The commercial activities dominate most of the spaces. A small pocket spaces in road intersection at JMI provide a space good enough for other types of transactions such as night market and thematic bazaar, occasionally. The interactive relation among users is minimal since people were only focusing on buying and selling activities along the shophouses and fronting the shopping malls. One of the heavily used spaces in the city center is the entrance space of SOGO shopping complex in Jalan Tuanku Abdul Rahman. People used the space for both passive and active interaction -waiting, entertaining, eating, informal transaction, meeting, and also political rally. The strength of the place is further enhanced by the function of the place as a shopping attraction with a direct link to the public transport nodes.

I can see people come here continuously. Even though crowded, packed, uncomfortable, people still come. Friends invite me to come here; I also wanted to see what is so special about this place. When I am here, it is undeniable that this place is the best, it has everything [9] Female aged 20, student 
A student recalls the memorable moment watching buskers' performance at SOGO:

I have seen people busking in front of SOGO. Just for a short while. Wanted to rush home. Nothing else [R8] Female, aged 24 students.

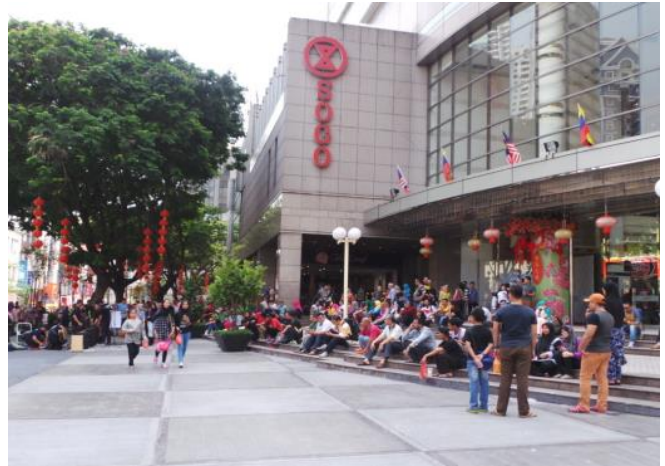

(a)

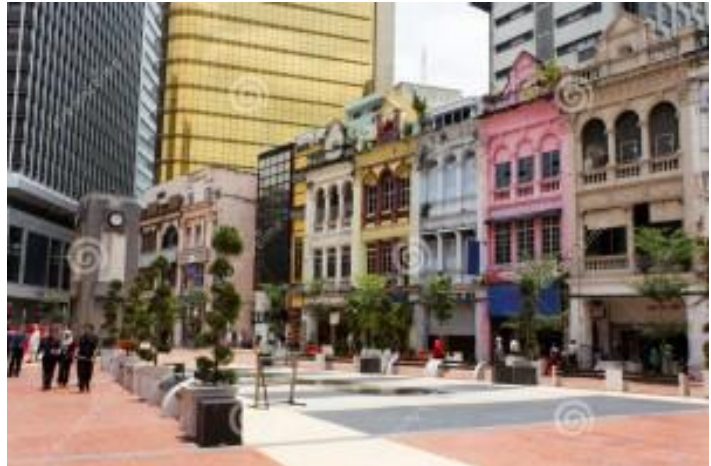

(b)

Fig. 1. People's activities at SOGO entrance (a) and open space of Medan Pasar (b)

4.3. The social attachment to the places are strongly defined by interaction with familiar people in place (ethnic relationship) and acquaintance who work in the area

Many felt comfortable associating with those from other ethnic backgrounds. However, the local users concerned about the issue of the overcrowding of immigrants in many public places and working in the many areas in the city. Also, they also addressed the concern regarding the presence of many mentally retarded people and beggars who slept in the public spaces that caused a bad image to the city. However, many didn't have a problem mixing or converse with others from a different ethnic background as well as tourists. The level of accessibility of public spaces is, therefore, is culturally oriented while feeling at ease with others surrounding the areas also expressed by the respondents.

"Everybody here is good, we are all handling our business. I don't have a problem to mix with others from other ethnicity, Workers from other shops; they are Malay, Chinese, together we talked." [R2]Female aged 39, shopowner

"I do mix with all people from other ethnic groups. Mixing with other ethnic actually is not a problem. I do like to make friend, we mixed well together." [R12]Female aged 42, shopkeeper 5 years engagement

"It is just that I don't like to see the presence of so many beggars despite the development of this area, as tourist attraction area, this should not have happened." [R4]Male aged 48, shopowner, 20 years engagement

The issue of a political demonstration was also addressed as 'negatively' affects their association with the places, in particular, Dataran Merdeka. The following addressed the feeling of uneasiness, however, peace demonstration is acceptable since it will not affect the business and social activities. The Dataran Merdeka is a famous square in the city and received many tourists. The fact that this square is a formal 'independence' space does not allow for many types of activities in the area. The activities mainly involve touring activities with less opportunity for longer stay due to the lacking of shaded spaces to sit and view the surroundings. The historical place has been associated with political rallies, which make the shopowners and sellers feel threatened by the rallies. However, the square has a very strong memory of Independence and pride of the country.

For the purpose of this paper, a sample area is presented based on the field observation. Table 1 indicates the assessment of Jalan Masjid India in terms of sociability/interaction. Despite the high rating for mixing of uses and the types of interactions, the opportunity for interactive contacts and shared activities is moderate to low due to the limitation of suitable spaces and facilities 
to do the activities. The streets are regarded as very active, mainly for commercial purposes, however lacking in supporting social interaction because of the lack of opportunity to sit and stay. The Recent addition of benches along Jalan Tuanku Abdul Rahman allows people to sit and rest in the middle of shopping activities despite the lack of shade.

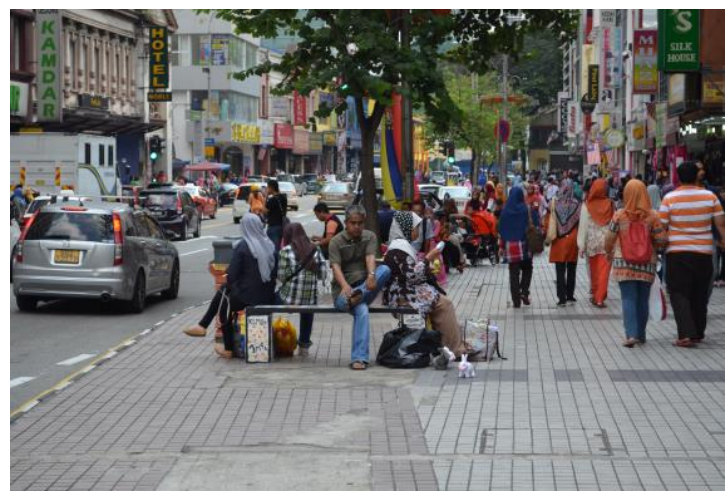

(a)

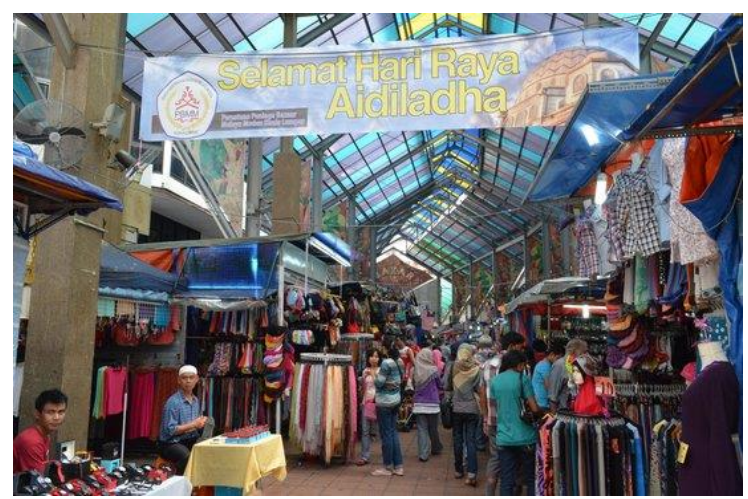

(b)

Fig. 2. Street lives in Jalan Tuanku Abdul Rahman (a) and Bazaar in Jalan Masjid India (b)

Table 1. Observation results on sociability and social interaction in Jalan Masjid India, Kuala Lumpur

\begin{tabular}{|c|c|c|c|}
\hline \multicolumn{2}{|c|}{ Sociability/Social Interaction } & Rating & Observation Notes \\
\hline \multirow[t]{2}{*}{1} & Variety of form of interaction & High & Mostly bargaining \\
\hline & & & $\begin{array}{l}\text { talking, eating, mixing, talking on mobile phone, greeting } \\
\text { others, observing others, promoting product }\end{array}$ \\
\hline \multirow[t]{2}{*}{3} & Variety of intensity of users who participate & Medium & Mostly people shopping, \\
\hline & & & Street performers but not that many stay to watch \\
\hline 4 & Variety in types of contacts & Medium & Physical contact \\
\hline 5 & Opportunity for contacts & Medium & Stairs for people to sit, food court \\
\hline \multirow[t]{2}{*}{6} & Level of users' involvement with activities & Moderate & Mostly people shopping, \\
\hline & & & Street performance but only few people watching \\
\hline 7 & Opportunity for sharing activities & Medium & $\begin{array}{l}\text { Space in front of the Mosque is suitable for shared activities, } \\
\text { but mostly shopping activities, walking and leisure walking }\end{array}$ \\
\hline 8 & Opportunity for conversing & Medium & $\begin{array}{l}\text { Space to converse at the entrance of the mosque, within the } \\
\text { compound but limited space }\end{array}$ \\
\hline 9 & Availability of shared spaces & $\begin{array}{l}\text { Very } \\
\text { limited }\end{array}$ & $\begin{array}{l}\text { An open space fronting the Masjid India Mosque and in front } \\
\text { of Semua House for chatting and eating; shaded space in } \\
\text { the street intersection at Jalan Bunus. }\end{array}$ \\
\hline 10 & Level of mixing of use & High & $\begin{array}{l}\text { Residential on top of shop houses, hotel, stall office, bank, } \\
\text { bazaar }\end{array}$ \\
\hline \multirow[t]{2}{*}{11} & $\begin{array}{l}\text { Opportunities to walk: suitable area, non- } \\
\text { obstacles, accessibility and good details to see }\end{array}$ & Moderate & $\begin{array}{l}\text { Suitable for walking, but need to be careful with cars } \\
\text { because there is no pedestrian crossing, narrow one-way } \\
\text { street. }\end{array}$ \\
\hline & & & Illegal parking, street vendor on walkways \\
\hline 12 & $\begin{array}{l}\text { Opportunities to stand and stay: attractive area } \\
\text { for standing or staying and supports for it }\end{array}$ & Low & $\begin{array}{l}\text { Limited space to stay and standing, except in front of the } \\
\text { mosque and next to the Hanifa store }\end{array}$ \\
\hline 13 & $\begin{array}{l}\text { Opportunities to see: interesting views with } \\
\text { reasonable view distance }\end{array}$ & Low & No interesting views, except bazaar, and cultural elements \\
\hline
\end{tabular}


Ujang, N., / $6^{\text {th }}$ AicE-Bs2015Barcelona, Spain, 30 Aug.- 04 Sep. 2015 / E-BPJ, Maiden Issue, 1(1) June 2016 (pp.28-35)

\begin{tabular}{llll}
\hline 14 & $\begin{array}{l}\text { Opportunities to sit outdoors: benches for sitting } \\
\text { and gathering }\end{array}$ & Moderate & $\begin{array}{l}\text { Limited space, a few benches close to bazaar and Mosque; } \\
\text { existing benches at the Hanifa store }\end{array}$ \\
\hline 15 & $\begin{array}{l}\text { Opportunities to talk and listen: low noise level } \\
\text { with interesting activities in front }\end{array}$ & Moderate & Noise from traffic and musical sound from shops \\
\hline 16 & Opportunities for playing and exercise & $\begin{array}{l}\text { Almost } \\
\text { none }\end{array}$ & Space not suitable for playing and exercise. \\
\hline
\end{tabular}

The study also examines the level of inclusiveness of the public spaces in Jalan Masjid India. Table 2 indicates that people from diverse age and gender used and visited the place. They were mainly Indian Muslim, Malay, and Indian. The presence of physically challenged users demands greater consideration on their needs while using the spaces. Despite having to offer a mixture of products and services, the opportunity to conduct and participate in social activities is moderate. This situation could be due to the types of businesses and transactions that focus on the wholesale trading and a few medium size shopping malls. The bazaar is the main form of transaction in the area because the nature of the business and the strategic location.

Table 2. Observation results on inclusiveness of public spaces in Jalan Masjid India, Kuala Lumpur

\begin{tabular}{llll}
\hline & Inclusiveness & Rating & Observation Notes \\
\hline 1 & Presence of people of diverse age & High & Children, teenagers, adult, elders \\
\hline 2 & Presence of people of different genders & High & Male and Female \\
\hline 3 & Presence of people in diverse races & Medium & Mostly Malay and Indian Chinese very low' Immigrant \\
\hline 4 & $\begin{array}{l}\text { Presence of people with diverse physical } \\
\text { abilities pregnant women }\end{array}$ & Medium & Elderly, Disable, Stroller \\
\hline 5 & Presence of lockable gates, fences & Low & Some part at shop \\
\hline 6 & $\begin{array}{l}\text { Perceived ability to conduct and participate in } \\
\text { activities and events in space }\end{array}$ & Moderate & Limited activity: Suitable for walking and bargaining \\
\hline 7 & $\begin{array}{l}\text { Mixed use development (mixture of different } \\
\text { uses) }\end{array}$ & High & Residential, commercial, hotel, bank, stall, office, bazar \\
\hline
\end{tabular}

The results indicate that the types of places and spaces influenced the opportunity for social interactions. The functions of the public spaces examined in this study have been influenced by the commercial activities. Therefore, the scale of users who participated in the public spaces varies according to the ability of the spaces to attract people to stay. The more flexible and multi-functioned is the space; the stronger the attractors will be. Street edges are very active along the five-foot corridor, however, failed to hold passers-by attention to stay because of the transactions and pedestrian movement. The lack of spaces provided for shared activities was evident in the street design despite being pedestrianized because of the dominant presence of street vendors. Spaces for connecting people could only be found in a formal park or a square that normally are disassociated with the major concentration of pedestrians. The level of mixing of use in park and square is very limited, therefore, become dull. The streets were not seen as a social space for social interaction, rather as a place to get people needs and could be considered 'private' and inaccessible when the spaces are redefined as an extension of the shops. The need to integrate with other types of uses will increase the potential for stronger engagement and diverse interactions. One good example is the proximity between the Masjid India and the Bazaar. We could observe not only passive interaction (buying and selling) but also active interaction where people were talking and discussing in front of the mosque while observing people walking. The space at the entrance of the mosque allows those activities to take place longer while continuing religious activities in the mosque and its compound.

\section{Conclusion}

A good urban place provides spaces for social and cultural transactions through friendship, events and occasions thus allow social attachment to be cultivated amongst the users. Social activities are dependent on other activities while the physical environments influence the conditions for social contacts. The social and cultural attachment should allow for an opportunity for interactive contact if the conditions of the spaces are flexible and adequate to be used for multi-functions. In the case of Kuala 
Lumpur city center where shopping streets have a more dominant role as social spaces compared to parks. Thus, place attachment should be developed as a result of social contact and should not be limited to business transactions. It is recommended that urban designers to create inclusive public spaces by providing places to sit and stay along the building frontages and important nodes in the city. The need for universal design is of necessity if the city wishes to reflect a socially conducive environment for all walks of life, young and old, able and physically challenged.

\section{Acknowledgement}

The author would like to acknowledge the Universiti Putra Malaysia, in funding and facilitating this research; under Putra Grant Scheme (PG-IPB).

\section{References}

Adams, D and Tiesdell, S (2008). The vital city. Town Planning Review, 78(6), 671-680.

Al-Bishawi and Ghadban (2011). A methodological approach for reading urban open space. Archnet-IJAR International Journal of Architectural Research. 1, 7385

Barnett E, Casper M. (2001). A definition of "social environment". American Journal of Public Health, 91(3):465

Cacioppo, J. and William Patrick, W. (2008). Loneliness: Human nature and the need for social connection. New York: Norton \& Company Incorporated.

Dempsey, N. et al., (2011). The social dimension of sustainable development: Defining urban social sustainability. Sustainable Development, $19(5)$, pp.289 300. Available at: http://doi.wiley.com/10.1002/sd.417 [Accessed July 4, 2012].

Francis, J., Giles-Corti, B., Wood, L., and Knuiman, M. (2012). Creating sense of community: The role of public space. Journal of Environmental Psychology, 32(4), 401-409.

Gehl, J. (1971). Life between buildings: Using public spaces. London: The John Hopkins University Press.

Gehl, J. (2013). Cities for people. Washington DC. : Island press.

Harun, N. Z., Zakariya, K., Mansor, M., \& Zakaria, K. (2014). Determining attributes of urban plaza for social sustainability. Procedia-Social and Behavioral Sciences, 153, 606-615.

Marans, R.W. (2012). Quality of urban life studies: an overview and implications for environment-behaviour research. Procedia - Social and Behavioral Sciences, 35 (2012), 9 - 22.

Mehta, V. (2014). Evaluating public space. Journal of Urban Design, 19(1), 53-88.

Parera, N. and Tang, S.W. (2013). "In search of Asian Urbanism" In transforming Asian Cities. Abingdon Oxon: Routledge.

Polèse, M., \& Stren, R. E. (2000). The social sustainability of cities: Diversity and the management of change. Toronto: University of Toronto Press.

Oktay, D. (2012). Human sustainable urbanism: In pursuit of ecological and

social-cultural sustainability. Procedia - Social and Behavioral Sciences, 36, (2012) 16 -27.

Oldenburg, R. (1999). The great good place. New York: Marlowe \& Company.

Stedman, R. C. (2003). Is it really just a social construction? The contribution of the physical environment to sense of place. Society \& Natural Resources, 16, 671-685.

Stokols, D., \& Shumaker, S. A., 1981. People in places: a transactional view of settings. In J. Harvey (Ed.), Cognition, Social Behavior and Environment (pp. 441-488). Hillsdale, NJ: Erlbaum.

Thwaites et al, \& lan M. Simkins (2009). Experiential landscape: an approach to people, place and space. New York: Routledge.

Ujang, N. (2010). Place attachment and continuity of urban place identity. Asian Journal of Environment-Behavior Studies, 11, 41-74.

Ujang, N. (2014). Place meaning and significance of the traditional shopping district in the city centre of Kuala Lumpur, Malaysia. ArchNet-IJAR International Journal of Architectural Research: Vol 8, No. 1, pp. 66-77.

Ujang, N. and Samsuddin, S. (2008). Place attachment in relation to users' roles in the main shopping streets of Kuala Lumpur. Urban design issues in developing world Edited by Ahmad Bashri Sulaiman and Moukhtar.M.Mai. pp. 22-41, UTM Press.

Ujang, N., \& Zakariya, K. (2015). The notion of place, place meaning and identity in urban regeneration. Procedia-Social and Behavioral Sciences, $170,709-717$. UN-HABITAT (2011). Global report on human settlements 2011: Cities and climate change. Nairobi, London: Earthscan, UN-HABITAT

Utaka, Y. and Fawzi, M.A. ( 2010). In "On Asian Streets and Public Space", edited by Heng Chye Kiang \& Low Boon Liang with Hee Limin, Ridge Books, Singapore

Zakariya, K., and Harun, N. Z. (2013). The people's dataran: Celebrating historic square as a potential temporary market space. Procedia-Social and Behavioral Sciences, 85, 592-601. 